\title{
Epiural anaesthesia: Superior modality of treatment in lower segment caesarean section in a patient with supracardiac TAPVC
}

\author{
Aniket Raosaheb Rakhunde ${ }^{1}$, Chetan Gopal Agrawal ${ }^{2 *}$, Dattatraya Gangurde ${ }^{3}$, Sumit Harishchandra Meshram ${ }^{4}$ \\ 1,4Junior Resident III, ${ }^{2}$ Senior Resident, ${ }^{3}$ Associate Professor, Dept. of Anaesthesia, GMCH Aurangabad, Maharashtra, India
}

*Corresponding Author: Chetan Gopal Agrawal

Email: drchetanagrawal87@gmail.com

\begin{abstract}
Background: Total Anomalous Pulmonary Venous Connection (TAPVC) is congenital heart disease in which the pulmonary veins do not connect normally to left atrium. Instead they connect to right atrium, often by way of systemic vein. There may be associated cardiac malposition. Anaesthetic management requires detailed assessment of cardiac an extracardiac anomalies \& its pathophysiological effects. Here we report a case of TAPVC posted for LSCS and its successful management.

Case Presentation: 25yrs female known case of TAPVC at 34.5 wks of gestation admitted 3 weeks prior, Vitaly stable, we did this patient under plain epidural anaesthesia without haemodynamic instability.

Conclusions: Epidural anaesthesia a better technique than general anaesthesia for supracardiac TAPVC posted for LSCS. Meticulous intraoperative monitoring is important. Cardiac Output must be maintained, avoid fall in Systemic Vascular Resistance (SVR) ensuring minimal change in shunt.
\end{abstract}

Keywords: Supracardiac TAPVC, LSCS, Epidural Anaesthesia.

\section{Case Presentation}

25yrs female patient known case of TAPVC at 34.5 wks of gestation admitted 3 weeks prior her 2D-ECHO findings were: Supracardiac TAPVC, dilated RA/ RV/ pulmonary arteries/moderate Pulmonary Hypertension, Normal Bilateral ventricular function, Non restrictive OS ASD, Right to Left shunt, LVEF 55\%, Pulmonary Artery Systolic Pressure $50 \mathrm{mmHg}$. Other lab investigations were normal. Patient was not on any medication.

Standard hemodynamic monitoring including Spo2, NIBP, ECG was establised Preop vital parameters were HR: 92/min, NIBP: 130/80 mmhg, RR: 18/min, Spo2: $98 \%$ with 02 support. 18G IV cannula secured. Patient gradually preloaded with $300 \mathrm{ml}$ RL. Our Plan of anaesthesia was Plain Epidural Anaesthesia. In sitting position under all aseptic precautions Painting and Draping done. 16G epidural catheter inserted in T12-L1 interspace, epidural space felt at $4 \mathrm{~cm}$ and catheter fixed at $9 \mathrm{~cm}$. Test dose of $2 \%$ lidocaine $3 \mathrm{cc}$ was given (Avoided adrenaline as heart disease). Followed by Inj. Ropivacaine $0.5 \% 14 \mathrm{cc}$ with Inj.fentanyl $25 \mu$ given. Block level achieved upto T6 level. LSCS was done with in $45 \mathrm{~min}$, patient was vitally stable throughout then shifted to PACU for $24 \mathrm{hrs}$ monitoring.

\section{Discussion}

The current status of pregnant patient with heart disease has been improved because of advancement in treatment and management. Earlier patients with cardiac disease were strongly discouraged from becoming pregnant, now with vast improvement in reproductive technology and cardiac care, cardiac patients are planning for pregnancy. Cardiologist, Gynaecologist, Anaesthesiologist should discuss the problem and line of management should be decided. $^{1}$

The advantage of regional anaesthesia is that patient can report any symptoms as palpitations, chest pain, breathlessness. Advantage of epidural anaesthesia will be gradual hypotension which can be controlled. ${ }^{1}$ Proper precautions should be taken while injecting IV drugs, avoid injecting single cc of air intravenously because it may cause paradoxical air embolism.

\section{Conclusions}

Epidural anaesthesia a better technique than general anaesthesia for supracardiac TAPVC posted for LSCS. Meticulous intraoperative monitoring is important. Cardiac Output must be maintained, avoid fall in Systemic Vascular Resistance (SVR) ensuring minimal change in shunt.

\section{Source of Funding}

None.

\section{Conflict of Interest}

None.

\section{Acknowledgements}

The authors thank nursing and paramedical staff associated with operation theatre. Special thanks to Obstetrics and Gynaecology department for their co-operation.

\section{References}

1. Chohan U, Afshan G, Mone A. Anaesthesia for caesarean section in patients with cardiac disease. J Pak Med Assoc. 2006;56(1):32-8.

2. Chestnut DH. Principles and practice of obstetric anaesthesia Elsevier Mosby-Philadelphia, Pennsylvania 2004;3:707-33.

3. Khanna S, Choudhary M. TAPVC postoperative problems and management, IJA. 2009;53(1):71-4.

4. Ross FJ, Joffe D. Perioperative and anesthetic considerations in TAPVC. Semin Cardiothorac Vasc Anesth. 2017;21(2):13844.

5. Mishra L, Pani N, Samantaray R, Nayak K. Eisenmengers syndrome in pregnancy: Use of epidural anesthesia and 
analgesia for elective CS. J Anasth Clin Pharmacol.

2014;30(3):425-6.

6. Biswas RG, Bandyopadbyay BK, Sarka M, Starkar UK, Gaswami A, Mukhejee P. Perioperative management of pregnant patient with heart disease for caesarean section under anaesthesia. JPMA. 2003;8:1-7.

How to cite: Rakhunde AR, Agrawal CG, Gangurde D, Meshram SH. Epiural anaesthesia: Superior modality of treatment in lower segment caesarean section in a patient with supracardiac TAPVC. Panacea J Med Sci. 2020;10(1):54-5. 